\title{
Albarrán Iruela, J. (2020). Ejércitos benditos: Yihad y memoria en Al-Andalus (siglos X-XIII). Granada: Editorial Universidad de Granada. 540 pp. ISBN: 978-84-338-6753-7
}

David PORRINAS GONZÁLEZ

\section{Author:}

David Porrinas González

Área de Didáctica de las Ciencias Sociales, Departamento de Didáctica de las Ciencias Sociales, Lengua y Literatura. Universidad de Extremadura (Spain)

dporrinas@unex.es

https://orcid.org/0000-0003-1759-6616

Date of reception: 22/07/21

Date of acceptance: 27/07/21

\section{Citation:}

Porrinas González, D. (2021). Book review: Albarrán Iruela, J. (2020). Ejércitos benditos: Yihad y memoria en Al-Andalus (siglos $\mathrm{X}-\mathrm{XIII}$ ). Anales de la Universidad de Alicante. Historia Medieval, (22), 403-408

https://doi.org/10.14198/medieval.20522

(C) 2021 David Porrinas González

Licence: This work is licensed under a Creative Commons Attribution 4.0 International License (CC BY 4.0).

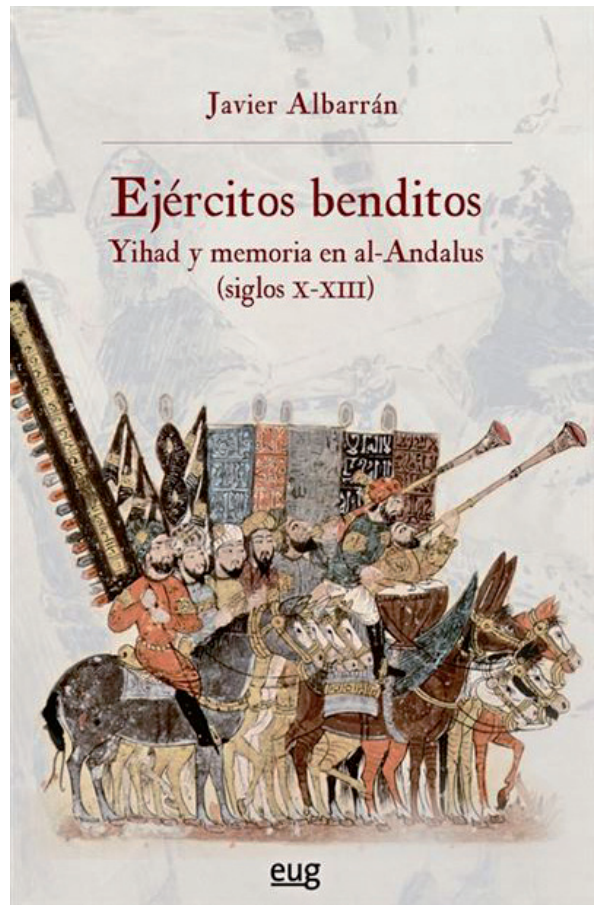

Ejércitos benditos, de Javier Albarrán, es un trabajo de investigación profundo sobre una cuestión muy poco tratada por la historiografía especializada en al-Andalus. Y es que sobre la plasmación y evolución de la guerra santa en el Islam occidental medieval es realmente poco lo que se ha estudiado, con honrosas excepciones como el propio Albarrán o el profesor Alejandro García Sanjuán. El libro es una versión resumida y adaptada de su tesis doctoral, defendida a principios del 2020, en el marco del Proyecto de Investigación I+D+i Violencia religiosa en la Edad Media peninsular: guerra, discurso apologético y relato historiográfico, dirigido por los profesores Carlos de Ayala Martínez y J. Santiago Palacios Ontalva, y financiado por la Agencia Estatal de Investigación del Ministerio de Economía y Competitividad del Gobierno de España (HAR2016-74968-P). A pesar de la densidad y la complejidad de lo 
estudiado, Albarrán logra condensar en poco más de 500 páginas años de arduas e intensas investigaciones sobre el $\hat{y} i h \bar{a} d$ y su implementación en el al-Andalus de los siglos plenomedievales. Escrito con un estilo ágil y profesional, riguroso y ameno, el lector podrá sumergirse en el mundo de las ideas religiosas, políticas, militares e ideológicas, en un momento de cambio en el devenir de las estructuras políticas peninsulares.

El propósito del autor es el de desentrañar un concepto de ŷihād que va más allá de su significación como "guerra santa", para luego centrarse en los distintos desarrollos y usos que adoptó el concepto y la práctica de la guerra sagrada en alAndalus desde el califato omeya hasta el imperio almohade, así pues, entre los siglos $\mathrm{X}$ y XIII. En los discursos sobre guerra santa va a cobrar una importancia capital la legitimación dada por el recurso a la memoria de las primeras batallas del Islam, aquellas que fueron libradas por el profeta Mahoma y sus sucesores más inmediatos, los primeros califas. Es precisamente a la clarificación de conceptos esenciales como los de "yihâad", "memoria" y "guerra santa" en lo que centra Javier Albarrán sus esfuerzos en el primer capítulo de la obra. También contextualiza el espacio y el tiempo donde centra su análisis, el al-Andalus desde el 912, cuando sube al trono Abderramán III, hasta el año 1269, cuando cae el Imperio Almohade. En ese arco temporal distingue tres fases diferenciadas, la del califato de Córdoba, la de los reinos de taifas y el dominio almorávide, y la de la presencia almohade en el ámbito andalusí. Como advierte Albarrán, un estudio de esta naturaleza no debe centrar su atención únicamente en la península Ibérica y al-Andalus, debiendo conocer y comprender, además, las dinámicas históricas que se están produciendo en el Magreb, e incluso más allá.

El objetivo fundamental del libro, en palabras del propio autor, es el de "estudiar los discursos de guerra santa que se pusieron en marcha en el al-Andalus de los siglos $X$-XIII", así como el de analizar el papel que desempeñó en esos discursos la memoria de las primeras batallas del Islam. En relación con ello, se valorará en el libro a la guerra santa como una herramienta esencial de poder y legitimación política e ideológica, y cómo pudo operar en la centralización de los distintos poderes islámicos andalusíes durante el periodo abordado. Para ello es necesario estudiar cómo son caracterizados los distintos enemigos contra los que se lanza la guerra santa, entendiendo, además, que el ŷihād no fue únicamente empleado por los principales soberanos. Finalmente, Albarrán entiende necesario analizar los elementos de ritualización de la guerra santa en este contexto.

Para centrar la importancia y alcance de su estudio, el autor realiza un apretado pero intenso ejercicio de historiografía, repasando las principales aportaciones de distintos estudiosos que, de una $\mathrm{u}$ otra manera, se han aproximado al complejo mundo de la guerra santa en al-Andalus, moviéndose principalmente en opiniones negacionistas del fenómeno en el contexto andalusí. Necesariamente todo buen his- 
toriador debe presentar sus fuentes, y reflexionar sobre ellas, sobre sus fortalezas y debilidades. Eso es precisamente lo que el profesor Albarrán hace en otro apartado de este primer capítulo introductorio. Y es que el repertorio de fuentes estudiado resulta amplio y heterogéneo, destacándose como vestigios más importantes los diccionarios biográficos, las fuentes jurídicas y literarias, las obras de magāzi y futūh, las fuentes documentales y epistolares y, fundamentalmente, las fuentes cronísticas, las cuales, como afirma el autor, resultan imprescindibles para un trabajo de esta naturaleza.

El capítulo 2 del libro se adentra en el estudio del primero de los periodos a tratar, el del califato omeya, en un arco temporal que Albarrán sitúa entre los años 912 y 1008. En ese contexto es necesario comprender la importancia del soberano, del califa, del autodenominado defensor del Islam y portador de seguridad y felicidad. Durante el califato las campañas militares serán lanzadas por el califa contra los enemigos de la fe con fines bélicos, ideológicos, legitimadores, y, por lo tanto, también políticos. Se aquilatará el concepto de "califa guerrero", que sufrirá a partir de la derrota en Simancas (939) un cambio de orientación y concepción. A partir de ahí el califa no participará tanto en las campañas de manera física como de forma espiritual, actuando como figura central en ceremoniales con alta carga simbólica como los anudamientos de banderas y la entrega de estandartes bendecidos. Almanzor recuperará, ya en los años finales del califato, un concepto y práctica del "califa guerrero" que se implica físicamente en el liderazgo y conducción de las campañas lanzadas contra los enemigos del Islam. Será esto así, según Javier Albarrán, por las necesidades legitimadoras de Almanzor, dándose durante su gobierno una mayor cantidad de expediciones militares lanzadas contra los cristianos especialmente.

Pero, ¿contra qué tipo de enemigos eran lanzadas esas campañas de guerra santa? En el siguiente bloque de este segundo capítulo es donde el autor caracteriza a esos distintos adversarios, que no son únicamente los cristianos del norte. Y es que la nómina de rivales debe ser completada con los "herejes, apóstatas e hipócritas", enemigos internos de una religión islámica considerada ortodoxa, disidentes y rebeldes que ocasionaban graves trastornos a un poder central califal que no dudó en emplear la guerra santa como mecanismo de control, cohesión, integración, sometimiento y centralización de la desviación y la disidencia.

En el siguiente bloque, Albarrán presenta algunos de los elementos más importantes de la ritualización de la guerra santa, siendo algunos de ellos las cartas, los alardes, las banderas y estandartes, y todo un programa propagandístico que tiene su desarrollo en los escenarios de organización y práctica de la guerra y en los relatos escritos de los mismos. Completaban el panorama todo un "display" diseñado para epatar al espectador, para hacer patente el poder religioso, político y militar del califa. En ese sentido, las tiendas rojas del califa en campaña eran auténticos símbolos de la guerra santa, así como las cartas de batalla y su fuerte carga de sacralización. 
Las cabezas cercenadas de los enemigos principales eran otra más de las manifestaciones de esa guerra sacralizada.

Pero la reivindicación y uso de la guerra santa no se limitaba al califa. Los señores de frontera, de origen árabe y beréber, responsables del gobierno y la defensa de demarcaciones en los confines de al-Andalus como Zaragoza o Toledo, aprovecharon también las ventajas que de cara a su propia legitimación ofrecía el capital simbólico de la guerra santa. Estos auténticos "virreyes de frontera", como los califica Albarrán, gozaron de amplios márgenes de autonomía respecto al poder califal, siendo precisamente su empleo de la guerra sagrada uno de los pilares de esa independencia relativa.

Pero... ¿Quiénes eran los receptores del programa de guerra santa propuesto por el poder? A esa importante cuestión dedica Javier Albarrán los siguientes bloques de este interesante segundo capítulo, donde analiza el poder de los voluntarios del $\hat{y} i h \bar{a} d$, motivados por la promesa de salvación que se ofrecía, y que en ocasiones tuvieron un desempeño que fue elogiado por los propios califas. No menos importantes fueron los hombres de religión y guerra, alfaquíes y ulemas que participaron en campañas bendecidas, y quienes, aun siendo ancianos en ocasiones, encontraron la muerte en empresas lanzadas contra infieles, descreídos, rebeldes y herejes. Algunos de estos hombres religiosos se retiraron a los confines de las fronteras para captar voluntarios de la guerra santa.

El último bloque de este capítulo caracteriza los elementos primordiales que materializan la guerra santa. La naturaleza martirial del combate es uno de ellos, así como la intervención en las batallas de agentes de Dios como los ángeles, o los sueños premonitorios inspirados por la divinidad, o el fuego divino lanzado contra los adversarios. La purificación e islamización del espacio conquistado a los infieles formaría parte también de ese programa ideológico y sacralizado.

El siguiente capítulo, el tercero, se adentra en el análisis de la memoria ancestral de las primeras batallas del Islam durante el periodo califal, estudiando analogías establecidas entre los califas de Córdoba y aquellos otros que iniciaron el Islam y su expansión mundial. Así, Abderramán III será contemplado como una especie de Mahoma redivivo por algunos autores que crean imágenes brillantemente analizadas por el autor. El Profeta será autoridad moral y religiosa recordada de manera recurrente por distintos eruditos y escritores, polemistas y propagandistas, y figura central en las comparaciones establecidas entre los soberanos del pasado y el presente.

Con todas esas bases sólidamente asentadas, Javier Albarrán nos sumerge en el capítulo 4 en la evolución de los conceptos, ya presentados, durante el interesante periodo de los reinos de taifas y el posterior dominio almorávide. Y es que, a pesar de la situación de debilidad que sufre al-Andalus durante las taifas, el recurso a las ideas de guerra santa, lejos de desaparecer, pervivió en algunos casos. Ciertamente en este tiempo se inclinó la balanza ofensiva a favor de los cristianos, pero algunos 
soberanos taifas no dejaron de recurrir a un combate sagrado más necesario que nunca, y algunos de esos reyes supieron seguir obteniendo rendimiento político y simbólico de la guerra contra el infiel y su sacralización. No obstante, el verdadero resurgimiento del concepto de soberano-gāzī va a producirse con la llegada e implantación del imperio almorávide en el contexto andalusí. Durante el dominio almorávide el predominio militar cristiano dará paso a un equilibrio de fuerzas, deteniéndose en las primeras décadas el empuje conquistador cristiano. Los almorávides lanzarán campañas exitosas contra el enemigo tradicional en el nombre de la fe, invocando la necesidad de ir más allá en el desarrollo de la guerra santa. Pero esa guerra santa no solo era necesaria contra los cristianos, lo era, en ocasiones más si cabe, contra movimientos religiosos que cuestionaban la autoridad de un movimiento almorávide que había surgido y se había consolidado fundamentándose en dos pilares principales: la religión y el ejército. Con esos dos sólidos puntales, los almorávides dominaron al-Andalus, enfrentándose por igual a reinos de taifas y reinos cristianos. Contra estos últimos cobrarán relevancia las decapitaciones, las oraciones, los estandartes e insignias, los discursos de las cartas de victoria, como impactantes muestras simbólicas del poder de Dios y los suyos, aun no documentándose cotas de intensidad equiparables al periodo califal.

Durante el periodo taifa-almorávide también se produjo el fenómeno de los señores de frontera, dominadores de territorios y necesitados de una legitimidad que incrementaba, precisamente, el recurso a la guerra sagrada. Igualmente se dio el voluntariado, la participación en campañas de hombres de religión y guerra, las connotaciones martiriales, las manifestaciones de la ayuda divina en la batalla, la islamización del espacio arrebatado al infiel. En el capítulo 5 Albarrán de nuevo vuelve a analizar el papel desempeñado por la memoria de las primeras batallas del Islam y la equiparación de los soberanos del presente con el Profeta y los primeros califas, en este caso durante el periodo tratado y cuajado en discursos elaborados por otros autores e intelectuales relevantes de ese tiempo y el posterior.

Similar estructura desarrolla el autor en el capítulo 6, destinado a reproducir el esquema analítico propuesto hasta ahora, para comprender los desarrollos del yìhäd durante el importante periodo almohade, que se inicia a mediados del siglo XII y se extiende hasta algo más de mediados del siglo XIII. Durante estos algo más de cien años, va a recurrirse de nuevo a la imagen y concepto de soberano-gāzī, quien apelará a la guerra santa como mecanismo útil para la unificación de territorios y la cohesión del dominio almohade. Y es que el poder almohade tendrá que enfrentarse en suelo andalusí a los tradicionales enemigos cristianos, que han retomado su expansión, y a otros poderes centrífugos como el ejercido por Ibn Mardanīš. Para ello se afinarán rituales, estandartes de victoria, reliquias y tambores, tiendas rojas del califa en la batalla, inscripciones en puertas monumentales de ciudades y fortalezas, las cartas de victoria expositivas de un lenguaje de guerra santa contundente y 
propagandístico. Durante el dominio almohade los poderes rebelados emplearán sus propios discursos y recursos de la guerra sagrada, y desde el lado califal se seguirá reflexionando sobre la naturaleza martirial del combate sagrado, la materialización de la ayuda divina, la participación de hombres de religión en los combates. La destrucción de los símbolos religiosos del enemigo será llevada a cabo durante el califato norteafricano.

De manera similar a lo trazado para los periodos califal y taifa-almorávide, Javier Albarrán profundiza, en un nuevo capítulo, en la recuperación y empleo intelectual y práctico de la memoria de las primeras batallas del Islam, dándose un intenso uso de esa memoria por parte de un poder califal almohade muy necesitado de legitimidad. Parte de esta memoria se verá enriquecida con el recuerdo de un pasado andalusí entendido como glorioso. Una vez más el autor desarrolla un profundo análisis de las obras de distintos autores del momento, y de sus percepciones sobre la memoria de batallas y pasados islámicos brillantes y memorables.

Se cierra la obra de Javier Albarrán con unas conclusiones generosas, maduras y acertadas, desarrollando en estas páginas una visión panorámica y analítica de las ideas y conceptos principales que ha venido desgranando con profundidad y rigor a lo largo de toda la obra. Soberano-gāzī, yi ihäd, centralismo versus desintegración, guerra santa como fuente e instrumento de cohesión, legitimidad y dominio político. Todos esos conceptos esenciales dibujan con nitidez un panorama que nos era bastante desconocido hasta ahora, contribuyendo el trabajo de Javier Albarrán a dar luz y color a un panorama de la guerra santa y sus facetas, que nos recuerda en no pocos aspectos a los desarrollos que se produjeron en el mundo cristiano enfrentado durante esos siglos. Ejércitos benditos contribuye, así pues, a un conocimiento más profundo de aspectos esenciales de la historia peninsular, y sienta las bases para en el futuro estar en condiciones de abordar estudios comparativos entre Islam y Cristiandad que pueden ser sumamente esclarecedores. 